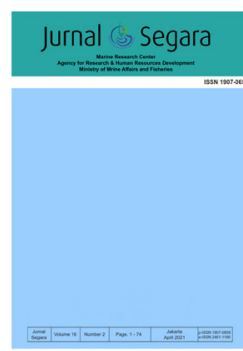

JURNAL SEGARA

http://ejournal-balitbang.kkp.go.id/index.php/segara

ISSN : 1907-0659

e-ISSN : 2461-1166

Accreditation Number : 766/AU3/P2MI-LIPI/10/2016

\title{
EVOLUTION OF SUBSURFACE TEMPERATURES IN WEST SUMATRA - SOUTHERN JAVA WATERS DURING 2010-2014 INDIAN OCEAN DIPOLE EVENTS
}

\author{
A.R. Khairun Nisa ${ }^{1)}$ \& Ivonne M. Radjawane ${ }^{1,2)}$ \\ ${ }^{1)}$ Graduate Program in Earth Science, Faculty of Earth Sciences and Technology, Bandung Institute of Technology \\ ${ }^{2)}$ Oceanography Study Program, Faculty of Earth Sciences and Technology, Bandung Institute of Technology \\ JI. Ganesa no.10, Bandung 40132, West Java, Indonesia
}

Received: 4 August 2021; Revised: 26 August 2021; Accepted: 31 August 2021

\begin{abstract}
The temperature anomaly formation in the West Sumatra and South Java Waters plays an important role in the formation of the Indian Ocean Dipole (IOD). There have not been many detailed studies on the evolution of temperature anomalies in the subsurface layers in the area during the IOD events. In this study, temperature data from the HYCOM were used to examine the evolution of temperature anomalies on the surface and subsurface in the event of negative IOD (nIOD) 2010 and positive IOD (pIOD) 2012). The analysis was done using a cross-section plot and a Hovmöller diagram. It has shown that in the negative IOD 2010, a positive temperature anomaly in the subsurface layer was started four months earlier than the surface layer and ended six months after the IOD event. In contrast to positive IOD 2012, a negative temperature anomaly formed in the surface layer seven months earlier, and then move to the deeper layer coincide with the onset of the positive IOD event. The negative anomaly in both layers was simultaneously over two months after the positive IOD event over. The La-Niña phase that coincides with the positive or negative IOD event, influences the process of forming temperature anomalies in the subsurface layer, which in this case supports (inhibits) the formation of positive (negative) temperature anomalies in negative (positive) IOD event. The temperature anomaly in the subsurface layer can be an alternative indicator in identifying and predicting IOD events.
\end{abstract}

Keywords: Indian Ocean Dipole (IOD), subsurface layer, la-Niña, West Sumatra waters, South Java waters. 


\section{INTRODUCTION}

The tropical Indian Ocean has an important contribution in the formation of the largest warm water pool on earth and its interaction with the atmosphere has also an important role in shaping climate on a regional and global scale (Schott et al., 2009). The phenomenon of displacement of warm water pools in the Indian Ocean that oscillates with an inter-annual period is called the Indian Ocean Dipole (IOD). This phenomenon is characterized by a hotter (colder) sea surface temperature anomaly in the western Indian Ocean and a cooler (hotter) anomaly in the eastern Indian Ocean (Saji et al., 1999).

In addition to the anomaly of sea surface temperature during the IOD events also will be followed of changing some parameters such as sea surface height (Fadlan et al., 2017; Zhou et al., 2015), salinity (Sun et al., 2019; Yuhong et al., 2013), chlorophyll-a concentration (Currie et al., 2013; Pandey et al., 2019), ocean heat content (Radjawane et al., 2015; Xia \& Wu, 2020), thermocline depth (Adiwira et al., 2018; Vinayachandran et al., 2009), and the variation in mixed layer depth (Keerthi et al., 2013; Santoso et al., 2010). Furthermore, IOD events will affect changing in climate conditions in the surrounding area, especially the rainfall intensity (e.g. Hatmaja et al., 2019; Hidayat \& Ando, 2018; Kurniadi et al., 2021; Nur'utami \& Hidayat, 2016; Risbey et al., 2009). The positive IOD event will cause decreasing rainfall over Sumatra Island, while the negative IOD event will increasing rainfall and sometimes lead to heavy rainfall season.

The West Sumatra until South Java Waters are the eastern part of the Indian Ocean, also known as the South-Eastern Tropical Indian Ocean (SETIO) area. The variability of SST anomalies in the waters of West Sumatra and South Java is influenced by several things, including the seasonal upwelling phenomenon generated by the wind and the influence of the Indonesian Throughflow or ITF (Delman et al., 2016). Furthermore, local winds in the South of Java generate upwelling while the SST anomaly is related to anomalies that occur in the Indian Ocean during the positive IOD phase. Equatorial wave also play an important role to generate SST anomaly during the IOD forming. The Rossby and Kelvin wave associated with easterly and westerly wind anomalies will generated zonal current caused sea surface temperature and sea level anomaly (Iskandar, 2012; Iskandar et al., 2013).Therefore, the SST anomaly formation process in this region has an important role in the IOD formation process. The heat balance analysis showed that air-sea heat exchanges play an active role in the SST anomaly during negative IOD. Meanwhile, the ocean heat advections mainly control temperature anomaly in the mixed layer depth during positive IOD event (Horii et al., 2013).

The temperature anomaly that occurs in the IOD event is not only formed in the surface layer but to the subsurface layers. In the 2006 positive IOD event, negative temperature anomalies were formed earlier than the surface layer (Horii et al., 2008). These results were obtained through analysis of observational data. Further research for positive IOD events in 2006-2008 that occurred consecutively also showed the same process, besides that anomalies formed in the lower layers would last longer than anomalies in the surface layers (Iskandar et al., 2014).

Based on the results of the research above, the temperature in the subsurface layer may be one of the parameters that can be used to better identify, predict, and understand the mechanism of formation of IOD events. Therefore, in this research, a study of the subsurface temperature evolution will be carried out by taking locations in the West Sumatra and South Java waters which are part of SETIO under two IOD conditions during 2010-2014.

\section{METHODOLOGY}

The research area is located from the West Sumatran waters through the southern of Java to West Nusa Tenggara waters (Figure 1). To obtain a better analysis of the study area, two transect lines (dashed green lines) were made, namely the A-B transect to represent the West Sumatran waters and the B-C transect for the southern waters of Java - West Nusa Tenggara (NTB). Furthermore, three observation points (black circles) were selected for each transect to be used in a more detailed time analysis. The coordinates of the start and end points of the transect as well as the observation points are presented in Table 1.

Temperature data from the surface layer to a depth of $300 \mathrm{~m}$ (assumed as subsurface layer) were obtained from the HYbrid Coordinate Ocean Model (HYCOM) which was further verified with NOAA's RAMA buoy observations located at coordinates $8^{\circ} \mathrm{S}$ and $100^{\circ} \mathrm{E}$ (shown by the star symbol in Figure 1). Data verification is done by calculating the Coefficient of Correlation, Root Mean Square Error (RMSE), and bias. The equation used is shown in Eq. (1) - (3).

$$
\begin{gathered}
C C=\frac{\sum_{i=1}^{N}\left(y_{i}-\overline{y_{i}}\right)\left(\widehat{y_{i}}-\overline{y_{i}}\right)}{\sum_{i=1}^{N}\left(y_{i}-\overline{y_{i}}\right)^{2} \sum_{i=1}^{N}\left(\widehat{y_{i}}-\overline{y_{i}}\right)^{2}} \\
\text { RMSE }=\sqrt{\left(\frac{\sum\left(y_{i}-\widehat{y_{i}}\right)^{2}}{n}\right)}
\end{gathered}
$$




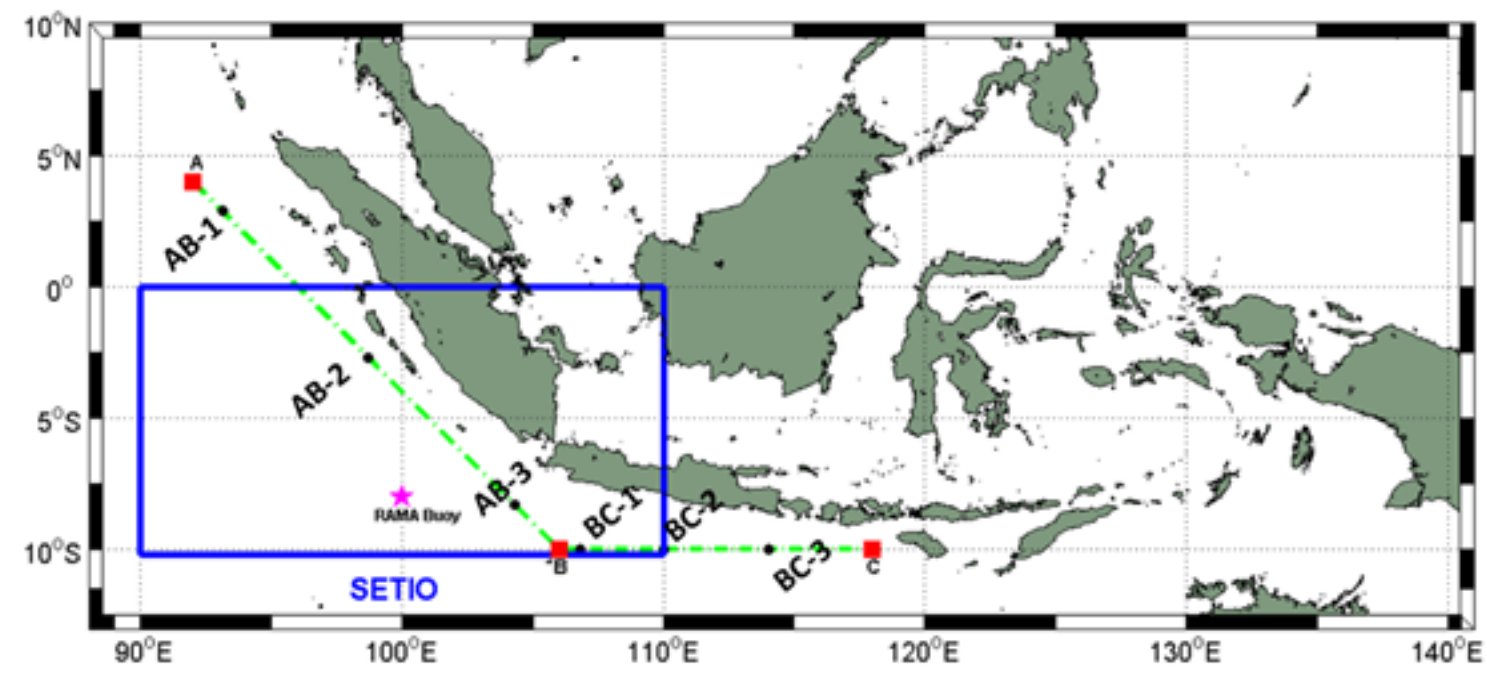

Figure 1. Research area. Blue rectangular indicated the SETIO area.

$$
\text { bias }=\frac{\sum\left(\widehat{y}_{i}-y_{i}\right)}{n}
$$

where $\mathrm{n}$ is number of data, $\hat{y}_{\mathrm{i}} \mathrm{i}$-th observation data, and $\hat{y}_{i} i$-th model data (for $\mathrm{i}=1,2,3, \ldots, \mathrm{N}$ ).

To test the significance of the correlation value (CC) we used T-test with confidence level 95\%. The T-test equation shown in Eq. (4).

$$
T_{\text {calculate }}=\frac{C C \sqrt{M-2}}{\sqrt{1-C C^{2}}}
$$

The spatial resolution of $\mathrm{HYCOM}$ is $1 / 12^{\circ}$ in the horizontal direction, while in the vertical direction a combination of isopycnal, sigma-z, and z-level coordinates is used. The temporal resolution performed on HYCOM is three hours which is then averaged to obtain daily data. The data that was obtained from HYCOM is daily sea temperature data for 20 years, from January 1995 to December 2014. This data is used to find monthly climatological anomaly values which are then used to find monthly temperature anomaly values in the study year. The data was filtered using the low-pass filter method with a cut-off period of 13 months to eliminate seasonal effects. To support the analysis, the Dipole Mode Index (DMI) and monthly Nino Index 3.4 data obtained from the calculation results of the Japan Agency for Marine-Earth Science and Technology (JAMSTEC) are also used.

\section{RESULTS AND DISCUSSION}

\section{Verification of Temperature Data}

Verification of vertical profile shown in Figure 2 for 2010 and Figure 3 for 2012. For both years, the vertical temperature profile from the observation data and the model has the same profile pattern, with increasing depth the temperature decreases. At a depth of 0-50 $\mathrm{m}$, the model results match the field measurement data, which is indicated by a line that coincides with an ambient temperature of $28^{\circ}-29^{\circ} \mathrm{C}$. The model results have a deeper mixed layer depth (MLD), which is up to a depth of $60 \mathrm{~m}$, while the observations show the MLD depth is around $40 \mathrm{~m}$.

A significant decrease in temperature occurs at a depth of $50-200 \mathrm{~m}$. In this layer, the observed temperature has a lower value than the model temperature. In June, there is a significant difference in values at a depth of 50-100 $\mathrm{m}$ with a difference of about $1^{\circ}-2^{\circ} \mathrm{C}$. Meanwhile, a significant difference occurs in July at a depth of 50-200 m with a difference of about $1^{\circ}-4^{\circ} \mathrm{C}$. From this vertical profile, can be concluded that vertically the two data have a similar profile, but at a depth of 50-200 m, the model data has a higher value than the observation data.

The results of calculating the CC and RMSE values for vertical profile data verification are shown in Table 2. For all months, the CC value is close to +1 . The t-test with a confidence level of $95 \%$ has been done to test the significance of the $\mathrm{CC}$ value. From the t-test, it is found that all CC values are significant, this indicates the model results can be used to perform analysis because the values can represent the actual value.

\section{Vertical Profile Temperature Anomaly}

Figures 4 and 5 show time series of the vertical profile of temperature at selected observation points. As the depth increases, the temperature anomaly increases. The maximum value of positive/negative temperature anomaly is in the depth range of $80-150$ $\mathrm{m}$, after a depth of $150 \mathrm{~m}$ there tends to be a decrease in the temperature anomaly value. 
(a)

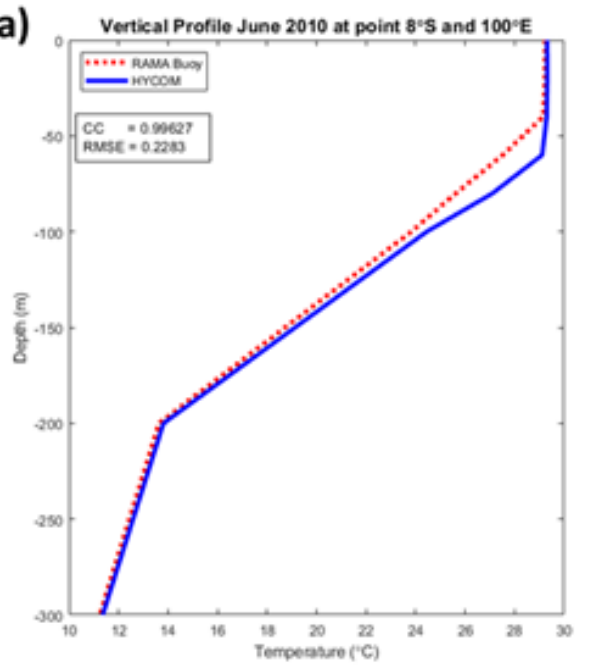

(b)

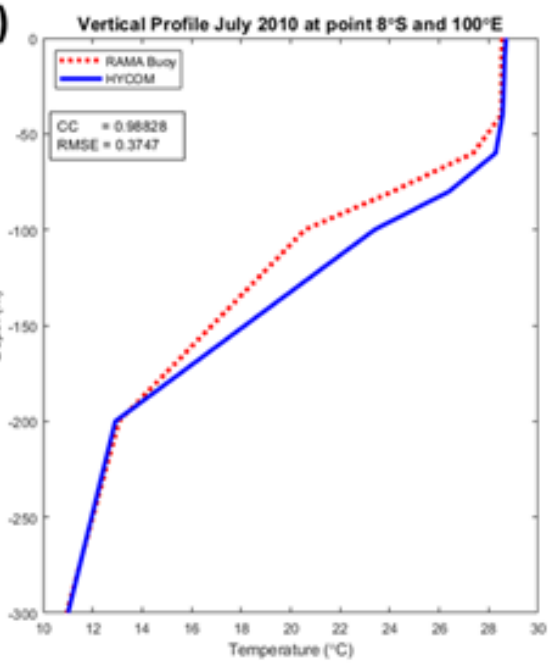

Figure 2. Verification of mean temperature vertical profile in (a) June 2010 and (b) July 2010. Blue line for HYCOM data. Dashed red line for observation data (RAMA buoy).

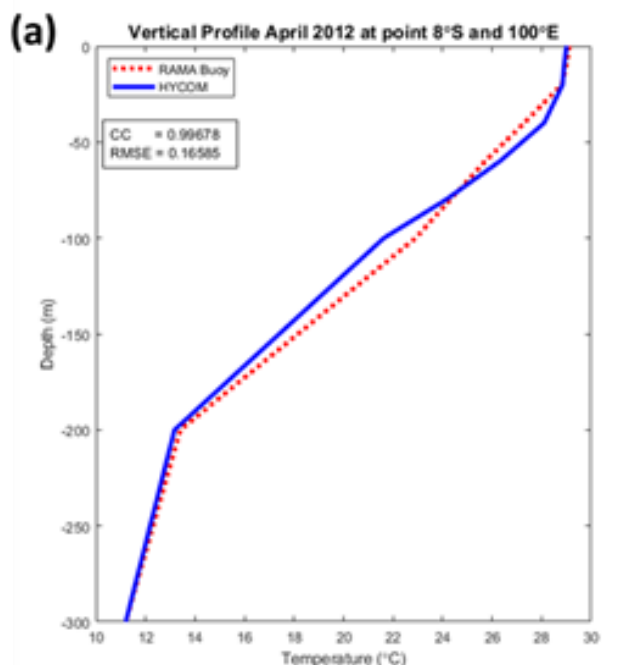

Figure 3. Same as Figure 2 for (a) April 2012 and

The thick black line in Figure $4 \mathrm{~b}-\mathrm{d}$ and Figure $5 b-d$ shows the $20^{\circ} \mathrm{C}$ isotherm line. The mechanism of initiation of IOD formation can be seen through the isotherm depth of $20^{\circ} \mathrm{C}$ (hereinafter referred to as T20), furthermore SST anomalies in the coastal areas of Sumatra and Java, have a significant correlation with T20 (Annamalai et al., 2003). Temporal changes in T20 depth (2010-2014) were reviewed at each selected observation point and presented in the form of a

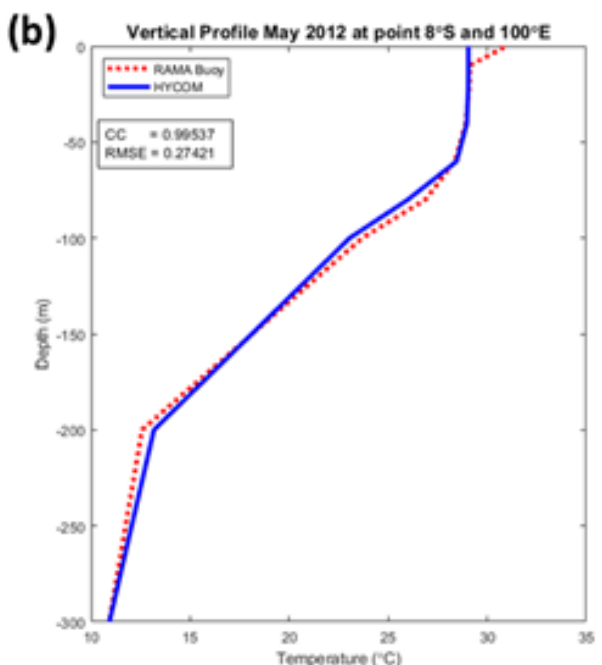

(b) May 2012.

Hovmöller diagram (Figures 4 and 5).

Negative SST anomaly will cause shallowing of T20, on the other hand, positive SST anomaly will cause T20 depth to increase. In February-March 2010 (Figure $4 \mathrm{~b}-\mathrm{d})$, the condition of the transect is dominated by negative temperature anomalies, in this condition the location of T20 is at a depth of $100 \mathrm{~m}$. In the following months, when positive anomalies began to form in the

Table 2.

CC and RMSE from vertical verification of mean temperature vertical profile

\begin{tabular}{lllll}
\hline Parameter & \multicolumn{2}{c}{$\mathbf{2 0 1 0}$} & \multicolumn{2}{c}{$\mathbf{2 0 1 2}$} \\
\cline { 2 - 5 } & June & July & April & May \\
\hline RMSE $\left({ }^{\circ} \mathrm{C}\right)$ & 0.228 & 0.375 & 0.166 & 0.274 \\
CC & 0.996 & 0.988 & 0.997 & 0.995 \\
t-test & Significant & Significant & Significant & Significant \\
\hline
\end{tabular}


subsurface layer, the location of T20 became deeper, at around $120-130 \mathrm{~m}$ depth. The strengthening of the positive anomaly in the subsurface layer that occurred from August to October caused T20 to become deeper, reaching a depth of $150 \mathrm{~m}$.

Although the value of the anomaly is reduced, the location of T20 still persists at around $150 \mathrm{~m}$ depth. In 2012 the negative temperature anomaly began to form in July in the surface to subsurface layers and strengthened in August (Figure 5b-c). This causes the depth of T20 which was originally around $120 \mathrm{~m}$ depth to become shallower, which is around $100 \mathrm{~m}$ depth in August. When the temperature warms up again causing the negative temperature anomaly to weaken in October, the location of T20 is again in a deeper layer.

The maximum depth of T20 occurred in October 2010 at a depth of $150 \mathrm{~m}$ with a positive anomaly value of $3.5^{\circ} \mathrm{C}$ (Figure $5 \mathrm{~b}-\mathrm{C}$ ). This condition coincided with the peak of negative IOD in 2010. The minimum depth of T20 occurred in the range of August - October 2012 at a depth of $100 \mathrm{~m}$ with a negative anomaly value of $-3^{\circ} \mathrm{C}$ (Figure $5 c-d$ ), this condition coincided with the occurrence of positive IOD.

\section{Surface Temperature Anomaly Analysis}

Based on the DMI value, it was found that the occurrence of negative IODn in 2010 and positive IODp in 2012. Negative IOD in 2010 occurred for three months, starting in August, and ending in October. Meanwhile, the 2012 IODp took place in a shorter time, namely for two months, starting in August and ending in September. Not only that, but there was also a strong La-Niña phase that occurred from mid-2010 to mid-2011, which was then followed by a weaker La-Nia phase in mid-2011 to mid-2012. List of IOD and ENSO events during 2010-2014 is shown in Table 3.

The negative IOD event in 2010 lasted for three months from August - October 2010. During that time, the positive temperature anomaly values in the surface layer ranged from $1^{\circ}-2^{\circ} \mathrm{C}$ in both transects (Figures $6 a$ and $7 a)$. There is a clear strengthening of the anomaly value in the eastern part of the $A-B$ transect (coordinates $100^{\circ}-106^{\circ} \mathrm{E}$ ), while on the $\mathrm{B}-\mathrm{C}$ transect, the positive temperature anomaly is amplified along the

Table 2.

CC and RMSE from vertical verification of mean temperature vertical profile

\begin{tabular}{llll}
\hline Event & Start & End & $\begin{array}{l}\text { Duration } \\
\text { (Months) }\end{array}$ \\
\hline nIOD & August 2010 & October 2010 & 3 \\
La Niña (strong) & May 2010 & April 2011 & 11 \\
La Niña (moderate) & June2011 & March 2012 & 7 \\
pIOD & August 2012 & September 2012 & 2 \\
\hline
\end{tabular}

(a)

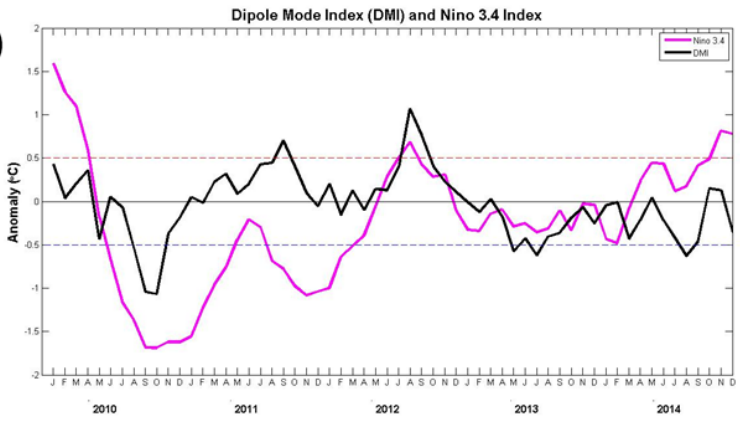

(c)

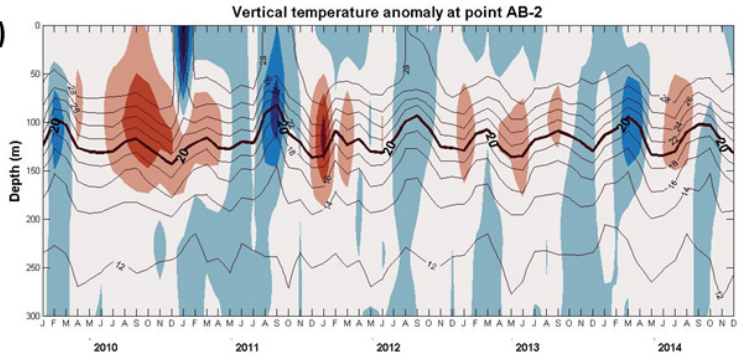

(b)

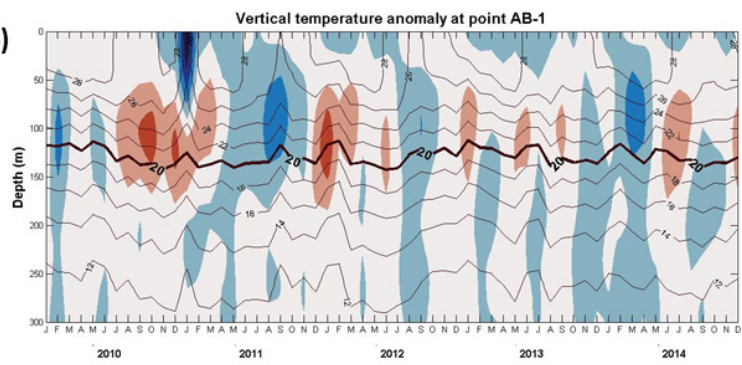

(d)

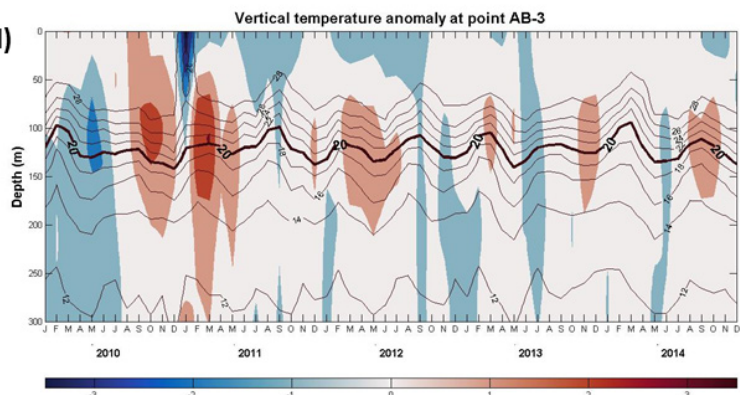

Figure 4. (a) DMI and Nino 3.4 Index 2010 - 2014. Plot Hovmöller time-depth at points (b) AB - 1, (c) AB -2 , (d) AB -3 . The thick line indicates the T20 line, the blue (red) color indicates the negative (positive) temperature anomaly. 
(a)

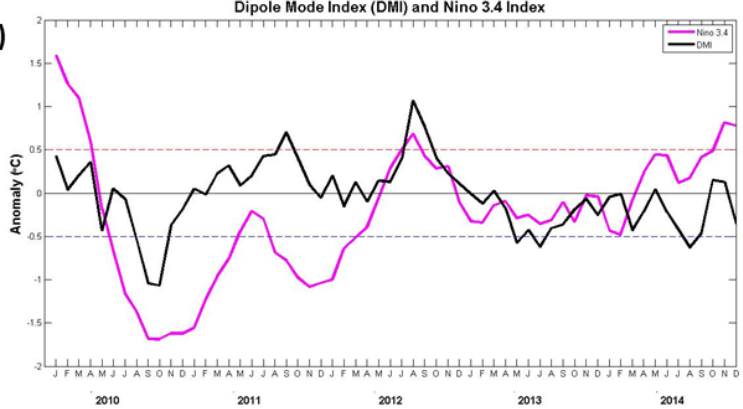

(c)

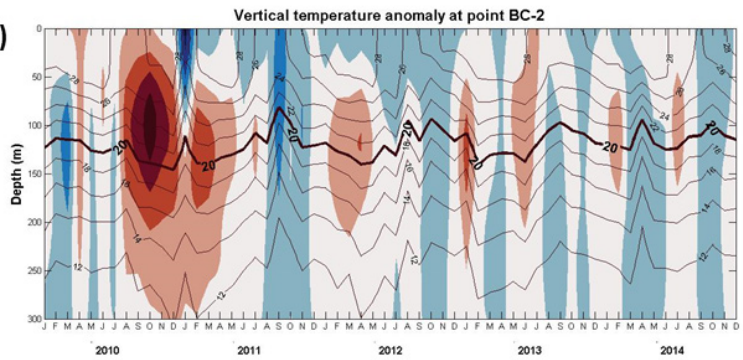

(b)

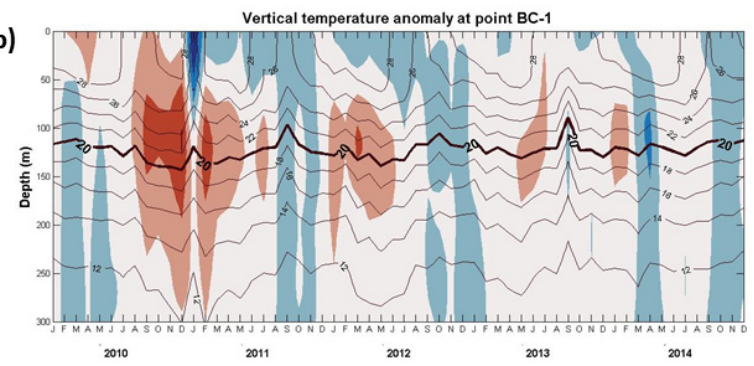

(d)

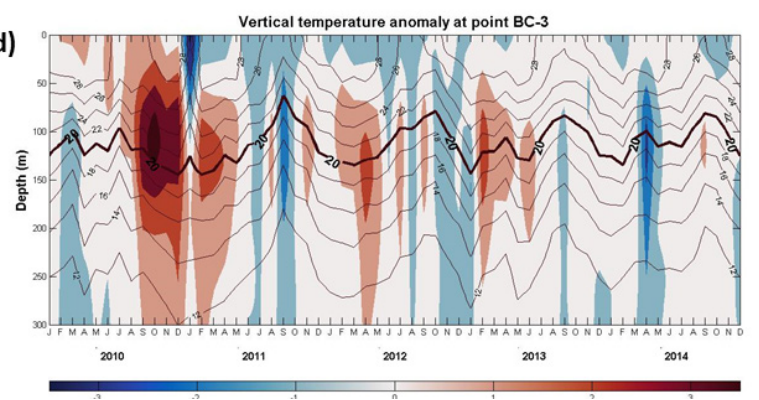

Figure 5. Same as Figure 4 for point (b) BC - 1,

transect. The anomaly began to appear and disappear at the same time as the start and end time of the 2010 negative IOD event. However, the positive temperature anomaly could still be found on the B-C transect even though the negative IOD event had ended. One of the factors causing the positive anomaly to still be found in the transect region $B-C$ even though the negative IOD event has ended is the strong La-Niña phase that occurred in the Pacific Ocean. This phase causes a mass supply of warm water to the Southern Java Waters (transect B-C) and causes conditions in the (c) BC - 2, (d) BC - 3 .

surface layer to warm.

Throughout 2011, conditions in the surface layer were dominated by negative temperature anomalies with values around $-1^{\circ}$ to $-2^{\circ} \mathrm{C}$. The weak La-Niña phase that occurred in 2011 did not have an impact on changes in the negative temperature anomaly that continued to occur in the Southern Waters of Java. In September-October 2011, there was a strengthening of the negative temperature anomaly in the surface layer, but the strengthening did not cause a positive
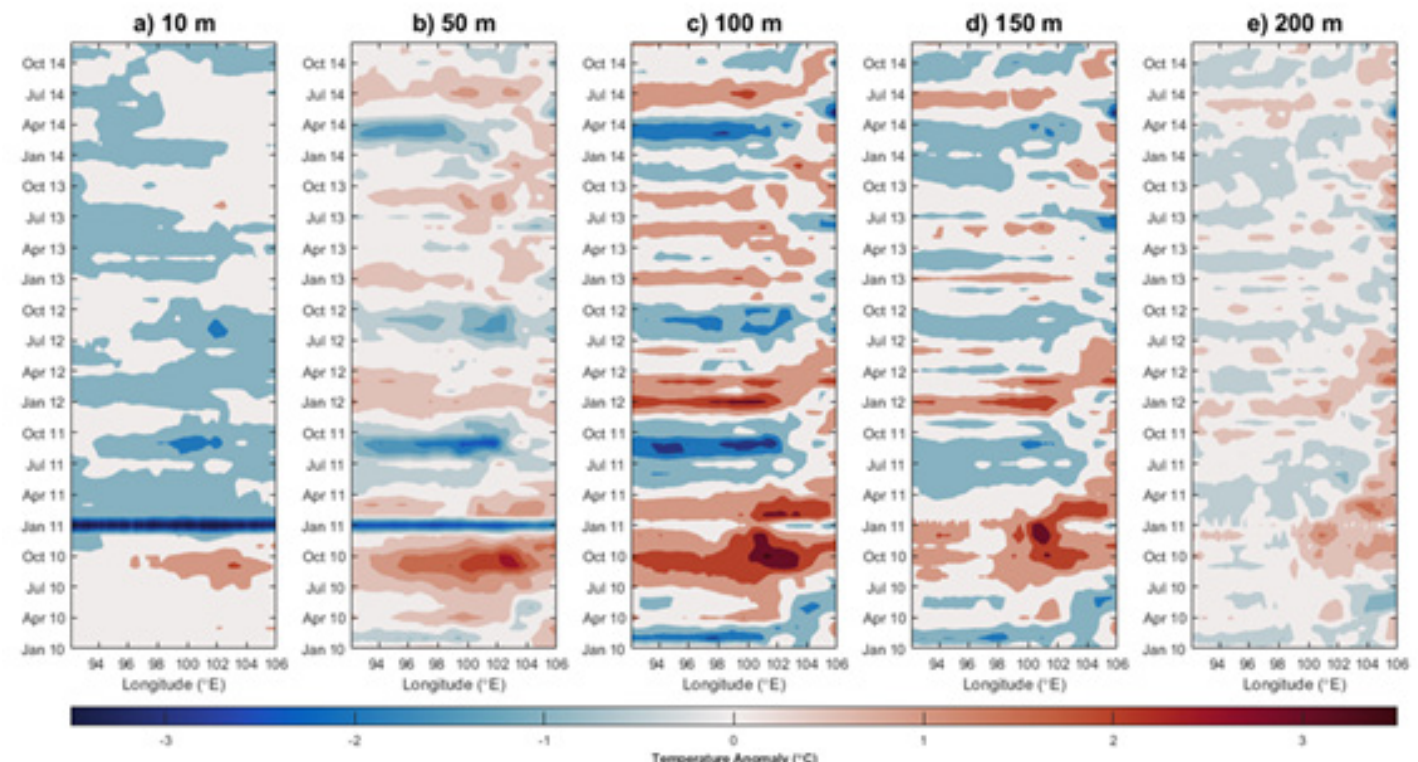

Figure 6. Hovmöller diagram of monthly temperature anomaly in the transect A-B at depths a) $10 \mathrm{~m}, \mathrm{~b}) 50$ $\mathrm{m}, \mathrm{c)} 100 \mathrm{~m}$, d) $150 \mathrm{~m}$, and e) $200 \mathrm{~m}$ during 2010-2014. 


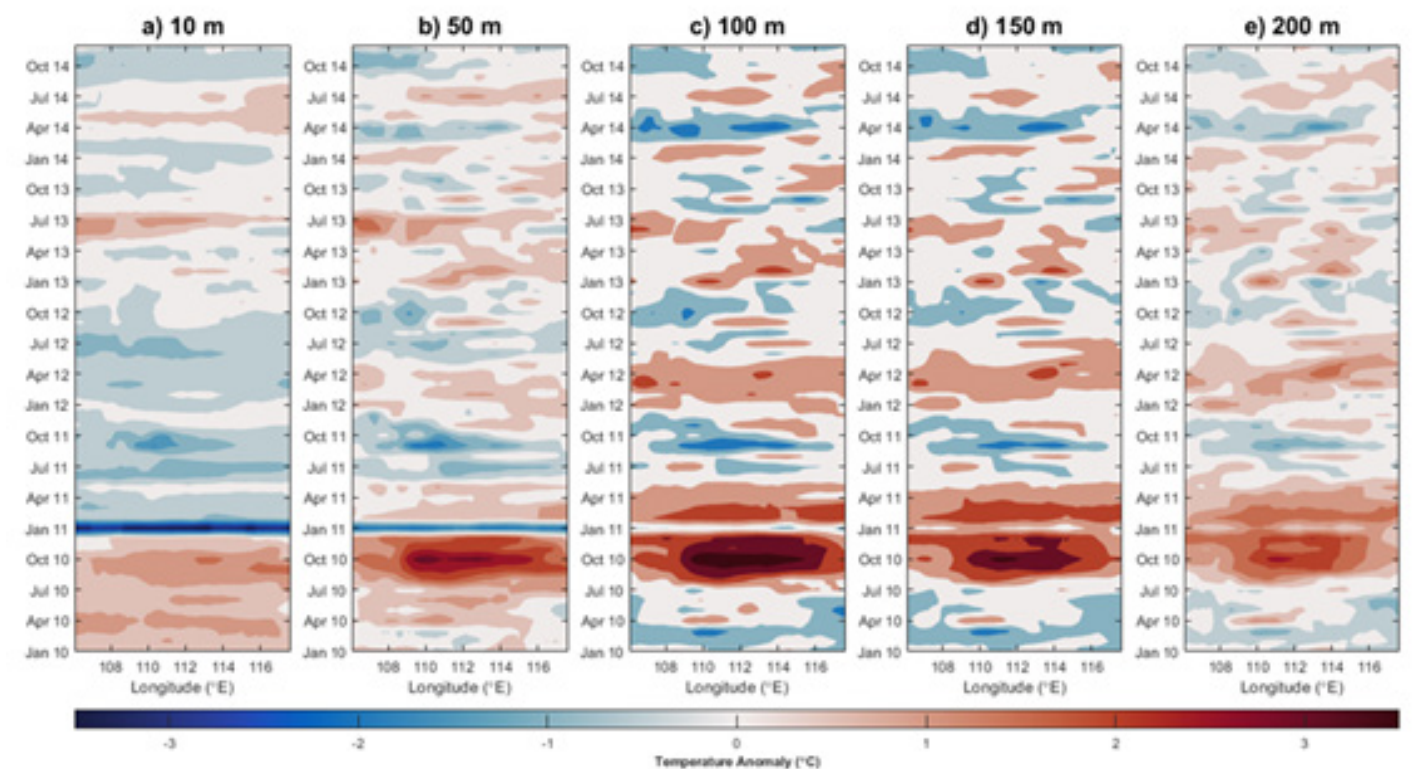

Figure 7. Same as Figure 6 for transect B-C.

\section{IOD condition.}

The strengthening of the negative temperature anomaly in the Southern Java waters can be caused by the local upwelling phenomenon generated by the wind. Previous studies have shown that upwelling in the waters of Sumatra and Java is heavily influenced by local winds along the coast associated with the southeast monsoon and remote winds caused by ocean-atmosphere interactions associated with ENSO. In normal years, in the waters of Sumatra and South Java, an upwelling phenomenon occurs in early June to mid-October, this phenomenon will begin to occur on the east coast of Java Island and move west-sea to an area of $104^{\circ} \mathrm{E}$ with a propagation speed of $0,2 \mathrm{~m} /$ sec. However, the alleged effect of upwelling from the results obtained in this study still needs to be studied further (Susanto et al., 2001).

The negative temperature anomaly began to strengthen in July 2012 which was then followed by the onset of positive IOD events in August (Figures 6a and 7a). However, this IODp event did not last long because in September the negative anomaly had weakened and even began to be faintly visible on the B-C transect. The absence of the El-Niño phase in the 2012 IODp event could be one of the reasons for the very short IODp period. From the results of previous studies, it is stated that most of the upwelling phenomena in South Java are influenced by the El-Niño phase in the Pacific Ocean, and partly influenced by the dynamics of the Indian Ocean itself (Susanto et al., 2001). The upwelling phenomenon that occurs in the waters of Java, Sumatra and the Lombok Strait has an important role in the mechanism for the formation of positive IOD (Delman et al., 2016). Thus, the absence of El-Niño events can reduce the upwelling phenomenon in the waters of Southern Java and West Sumatra which plays an important role in the formation of positive IOD events.

\section{Subsurface Temperature Anomaly Analysis}

The value of the positive/negative temperature anomaly in the subsurface layer has a greater value than the surface layer. In the event of negative IOD in 2010, a positive temperature anomaly on the transect A-B was formed in April, four months before the onset of the negative IOD event (Figure 6b-c). Meanwhile, on the B-C transect (Figure 7b-c), at a depth of $50 \mathrm{~m}$ and $100 \mathrm{~m}$, positive anomalies appear in January and August, respectively. The maximum positive anomaly value of about $3^{\circ}-3.5^{\circ} \mathrm{C}$ occurs during the peak phase of the negative IOD in September-October. This positive anomaly continues for two to six months after the end of the negative IOD event and then gradually turns into a negative temperature anomaly.

In contrast to the negative IOD incident in 2010, the positive IOD event in 2012 a negative temperature anomaly in the subsurface layer that coincided with the start of the positive IOD event (Figures 6b-c and $7 \mathrm{~b}$ c). As with the negative IOD, the maximum value of the negative anomaly occurs during the peak phase of the positive IOD in August-September with a value of around $-3^{\circ} \mathrm{C}$. The negative anomaly in the transect A-B disappeared along with the end of the positive IOD event, while in the transect B-C negative anomaly was still found two months later but with a lower anomaly value and then turned into a positive anomaly.

The results of the analysis show that there are differences in the evolution of the formation of 
temperature anomalies in positive and negative IOD events. In the negative 2010 IOD conditions, a positive temperature anomaly had formed in the subsurface layer several months ago. The evolution of temperature anomalies that occurred in the formation of positive IOD in 2012 was different from the positive IOD in 2006 -2008 which was studied by Iskandar et al. (2014). In the 2006 positive IOD, a negative temperature anomaly formed in the subsurface layer three months before the onset of the positive IOD event. The existence of differences in the evolution of temperature anomalies in the same type of event can be influenced by other physical phenomena, one of which may be local upwelling events caused by local and remote winds and the ENSO phenomenon that occurs in the Pacific Ocean.

\section{ENSO Phase Effect}

The strong La-Niña phase 2010-2011 and the moderate La-Nia 2011-2012 also contributed to the development of temperature anomalies in IOD events. In the El-Niño (La-Niña) phase, the ITF flow through the Lombok Strait and other straits will bring cooler (warmer) water masses to the Indian Ocean (Susanto et al., 2001). This resulted in the negative IOD in 2010 positive anomalies in the subsurface layer that were formed before the IOD event began and continued to occur even though the IOD event had ended. On the other hand, the La-Niña phase that still occurred in early 2012 prevented the formation of negative anomalies in the subsurface layer.

\section{CONCLUSION}

In the 2010 negative IOD event that coincided with the La-Niña phase (strong), the positive temperature anomaly appeared in the subsurface about four months before the start of the IOD event and the anomaly in the subsurface layer only ended six months later after the IOD event ended. Meanwhile, in the positive IOD event in 2012, negative temperature anomalies had formed in the surface layer before the onset of the IOD event. The anomaly only appeared in the subsurface layer with the start of the negative IOD event in August and disappeared gradually two months after the end of the IOD event.

In general, the value of negative and positive temperature anomaly has a greater value in the subsurface than in the surface layer. The maximum value of the positive temperature anomaly in the subsurface layer can reach a value of $>3.5^{\circ} \mathrm{C}$ while in the surface layer it is $2^{\circ} \mathrm{C}$. Furthermore, the value of the negative temperature anomaly in the subsurface is $-3^{\circ} \mathrm{C}$ and on the surface is $-1^{\circ} \mathrm{C}$. The existence of the 2010 - 2011 La-Niña Phase which coincided with the 2010 positive IOD event supported the formation of positive temperature anomalies in the waters of
West Sumatra and South Java, both in the surface and subsurface layers. Meanwhile, the 2011-2012 La-Niña phase inhibited the formation of negative temperature anomalies in the subsurface layer in the waters of West Sumatra and southern Java.

In its evolution, horizontally the temperature anomaly formed will move eastward, while in the vertical direction there are two possibilities, namely rising to the surface and moving down to the subsurface layer. In the 2010 negative IOD, the anomaly formed in the subsurface moves up to the surface layer. On the other hand, in the positive IOD event in 2012, the negative anomaly that had formed in the surface layer moved down to the subsurface layer.

From the results of previous studies that have been carried out, it shows that the temperature anomaly in the subsurface layer is different from the surface layer, besides that each positive or negative IOD event in different years will have a different evolution. The difference was caused by other phenomena that accompanied the IOD incident in that year. An understanding of the evolution of subsurface temperature in the formation of IOD events can be an alternative indicator to identify and predict IOD events in the future. However, further studies are needed by reviewing various scenarios of IOD events in other years, one of which is IOD events that are not accompanied by the ENSO phase.

\section{ACKOWLEDGEMENTS}

We would like to thanks to Marine Technology Cooperation Research Center (MTCRC) KoreaIndonesia for providing scholarships for the first author. Funding for the development of HYCOM has been provided by the National Ocean Partnership Program and the Office of Naval Research. Data assimilative products using HYCOM are funded by the U.S. Navy. Computer time was made available by the DoD High Performance Computing Modernization Program. The output of HYCOM is publicly available at https:// hycom.org. Thanks to General Bathymetric Chart of the Oceans (GEBCO), European Center for MediumRange Weather Forecasts (ECMWF), World Ocean Atlas (WOA) and Ocean Research Institute (ORI) for providing data to support this research.

\section{REFFERENCE}

Adiwira, H., Purba, N.P., Harahap, S.A., \& Syamsuddin, M.L. (2018). Variabilitas suhu laut pada kejadian IOD (Indian Ocean Dipole) di perairan barat Sumatera menggunakan data Argo Float. Depik, 7(1), 28-41. https://doi.org/10.13170/ depik.7.1.8089 
Annamalai, H., Murtugudde, R., Potemra, J., Xie, S. P., Liu, P., \& Wang, B. (2003). Coupled dynamics over the Indian Ocean: Spring initiation of the Zonal Mode. Deep-Sea Research Part II: Topical Studies in Oceanography, 50(12-13), 2305-2330. https://doi.org/10.1016/S0967-0645(03)00058-4

Currie, J.C., Lengaigne, M., Vialard, J., Kaplan, D. M., Aumont, O., Naqvi, S.W.A., \& Maury, O. (2013). Indian ocean dipole and El Niño/Southern Oscillation impacts on regional chlorophyll anomalies in the Indian Ocean. Biogeosciences, 10(10), 6677-6698. https://doi.org/10.5194/bg10-6677-2013

Delman, A.S., Sprintall, J., McClean, J.L., \& Talley, L.D. (2016). Anomalous Java cooling at the initiation of positive Indian Ocean Dipole events. Journal of Geophysical Research: Oceans, 121(8), 58065824. https://doi.org/10.1002/2016JC011635

Fadlan, A., Sugianto, D.N., Kunarso, \& Zainuri, M. (2017). Influence of ENSO and IOD to Variability of Sea Surface Height in the North and South of Java Island. IOP Conference Series: Earth and Environmental Science, 55(1). https://doi. org/10.1088/1755-1315/55/1/012021

Hatmaja, R.B., Rusmanansari, A.H., \& Radjawane, I.M. (2019). The dynamics of negative Indian Ocean Dipole (nIOD) and its relation to the anomalous high rainfall in West Java Province, Indonesia. IOP Conference Series: Earth and Environmental Science, 303(1). https://doi.org/10.1088/1755$1315 / 303 / 1 / 012004$

Hidayat, R., \& Ando, K. (2018). Variabilitas Curah Hujan Indonesia dan Hubungannya dengan ENSO/IOD: Estimasi Menggunakan Data JRA-25/JCDAS. Agromet, 28(1), 1-8. https://doi.org/10.29244/j. agromet.28.1.1-8

Horii, T., Hase, H., Ueki, I., \& Masumoto, Y. (2008). Oceanic precondition and evolution of the 2006 Indian Ocean dipole. Geophysical Research Letters, 35(3). https://doi. org/10.1029/2007GL032464

Horii, T., Ueki, I., Ando, K., \& Mizuno, K. (2013). Eastern Indian Ocean warming associated with the negative Indian Ocean dipole: A case study of the 2010 event. Journal of Geophysical Research: Oceans, 118(1), 536-549. https://doi. org/10.1002/jgrc.20071

Iskandar, I., Mardiansyah, W., Setiabudidaya, D., Affandi, A.K., \& Syamsuddin, F. (2014). Surface and subsurface oceanic variability observed in the eastern equatorial Indian Ocean during three consecutive Indian Ocean dipole events: 2006 2008. AIP Conference Proceedings, 1617. https:// doi.org/10.1063/1.4897101

Iskandar, I. (2012). The role of equatorial oceanic waves in the activation of the 2006 Indian Ocean Dipole. ITB Journal of Science, 44 A(2), 113-128. https://doi.org/10.5614/itbj.sci.2012.44.2.2

Iskandar, I., Irfan, M., \& Saymsuddin, F. (2013). Why was the 2008 Indian Ocean Dipole a short-lived event?. Ocean Science Journal, 48(2), 149-160. https://doi.org/10.1007/s12601-013-0012-3

Keerthi, M.G., Lengaigne, M., Vialard, J., de Boyer Montégut, C., \& Muraleedharan, P.M. (2013). Interannual variability of the Tropical Indian Ocean mixed layer depth. Climate Dynamics, 40(3-4), 743-759. https://doi.org/10.1007/s00382-012$1295-2$

Kurniadi, A., Weller, E., Min, S.K., \& Seong, M.G. (2021). Independent ENSO and IOD impacts on rainfall extremes over Indonesia. International Journal of Climatology, 41(6) 3640-3656. https:// doi.org/10.1002/joc.7040

Nur'utami, M.N., \& Hidayat, R. (2016). Influences of IOD and ENSO to Indonesian Rainfall Variability: Role of Atmosphere-ocean Interaction in the Indopacific Sector. Procedia Environmental Sciences, 33. https://doi.org/10.1016/j.proenv.2016.03.070

Pandey, S., Bhagawati, C., Dandapat, S., \& Chakraborty, A. (2019). Surface chlorophyll anomalies associated with Indian Ocean Dipole and EI Niño Southern Oscillation in North Indian Ocean: a case study of 2006-2007 event. Environmental Monitoring and Assessment, 191. https://doi. org/10.1007/s10661-019-7754-z

Radjawane, I.M., Bernawis, L.I., Priyono, B., Fadli, M., \& Putuhena, H.S. (2015). Interannual variation of ocean heat content in outer Indonesian waters in warming ocean (Case study: West Sumatra waters). AIP Conference Proceedings, 1677. https://doi.org/10.1063/1.4930695

Risbey, J.S., Pook, M.J., Mclntosh, P.C., Wheeler, M.C., \& Hendon, H.H. (2009). On the remote drivers of rainfall variability in Australia. Monthly Weather Review, 137(10), 3233-3253. https://doi. org/10.1175/2009MWR2861.1

Saji, N.H., Goswami, B.N., Vinayachandran, P.N., \& Yamagata, T. (1999). A dipole mode in the tropical Indian ocean. Nature, 401(6751), 360-363. 
https://doi.org/10.1038/43854

Santoso, A., Sen Gupta, A., \& England, M.H. (2010). Genesis of Indian Ocean mixed layer temperature anomalies: A heat budget analysis. Journal of Climate, 23(20), 5375-5403. https:// doi.org/10.1175/2010JCLI3072.1

Schott, F.A., Xie, S.P., \& McCreary, J.P. (2009). Indian ocean circulation and climate variability. In Reviews of Geophysics, 47(1). https://doi. org/10.1029/2007RG000245

Sun, Q., Du, Y., Zhang, Y., Feng, M., Chowdary, J. S., Chi, J., Qiu, S., \& Yu, W. (2019). Evolution of Sea Surface Salinity Anomalies in the Southwestern Tropical Indian Ocean During 2010-2011 Influenced by a Negative IOD Event. Journal of Geophysical Research: Oceans, 124(5), 34283445. https://doi.org/10.1029/2018JC014580

Susanto, R.D., Gordon, A.L., \& Zheng, Q. (2001). Upwelling along the coasts of Java and Sumatra and its relation to ENSO. Geophysical Research Letters, 28(8), 1599-1602. https://doi. org/10.1029/2000GL011844

Vinayachandran, P.N., Francis, P.A., \& Rao, S.A. (2009). Indian Ocean Dipole: Processes and impacts. Current Trends in Science.

Xia, H., \& Wu, K. (2020). Investigation of the Heat Budget of the Tropical Indian Ocean During Indian Ocean Dipole Events Occurring After ENSO. Journal of Ocean University of China, 19(3), pages 525-535. https://doi.org/10.1007/ s11802-020-4269-8

Yuhong, Z., Yan, D., Shaojun, Z., Yali, Y., \& Xuhua, C. (2013). Impact of Indian Ocean Dipole on the salinity budget in the equatorial Indian Ocean. Journal of Geophysical Research: Oceans, 118(10), 4911-4923. https://doi.org/10.1002/ jgrc.20392

Zhou, Q., Duan, W., Mu, M., \& Feng, R. (2015). Influence of positive and negative Indian Ocean Dipoles on ENSO via the Indonesian Throughflow: Results from sensitivity experiments. Advances in Atmospheric Sciences, 32(6), 783-793. https:// doi.org/10.1007/s00376-014-4141-0

National Oceanic and Atmospheric Administration. (NOAA). Accessed 13 July 2020 https://www. pmel.noaa.gov/tao/drupal/disdel/

Japan Agency for Marine-Earth Science and Technology. (JAMSTEC). (2020. Accessed 16 July 2020 from http://www.jamstec.go.jp/aplinfo/sintexf/e/index. html 